\title{
Escape learning deficit after overcrowded rearing in rats: Test of a helplessness hypothesis*
}

\author{
DANIEL J. GOECKNER. WILLIAM T. GREENOUGH \\ and STEVEN F. MAIER $\div$ \\ Lniversity of Illinois. Champaign. Ill. 61820
}

In a previous study, rats reared in overcrowded environments exhibited characteristics similar to those of the learned helplessness phenomenon described following exposure to inescapable shock. In the present study, rats reared alone or in groups of 4 or 32 for 50 days after weaning were tested in a shuttlebox, for which two successive crossings were required to avoid or escape shock. Ten rats from each population group received inescapable shock prior to shuttlebox training, while another 10 were identically handled, but not shocked. Rats given inescapable shock failed to perform the shuttlebox task, regardless of the size of the population with which they were reared. Rats not preshocked performed the shuttle task, although those reared in groups of 32 required several trials to reach the level of the smaller groups. The results indicate that impaired learning following overcrowded rearing does not result from helplessness-like behavior.

A number of recent reports have indicated that chronic exposure to overcrowded conditions may produce a variety of behavioral abnormalities. While some have attempted to assess the effects of high population densities in humans (e.g.. Galle, Gove, \& McPherson, 1972), the bulk of the data selectively evaluating overcrowding effects has come from animal studies. Experiments with rodents have indicated that population densities above a certain level tend to stress the animals, as indicated by both biological (e.g., Brain \& Nowell, 1970; Christian, 1955) and behavioral (Calhoun, 1962: Bell, Miller, Ordy. \& Rolsten, 1971) measures.

Recently, Goeckner, Greenough, \& Mead (1973) reported that rats reared from weaning under high population density conditions were inferior in performance on learning tasks, relative to low-density-housed animals from the same litters. The differences appeared on both appetitively and aversively motivated complex tasks, while no differences were apparent on simple tasks. While the results suggested possible differences in learning ability, the performance of several animals in the high-density groups indicated that differences in their reactions to the task itself might be involved. These animals, in a Y-maze light discrimination, would, after a few trials, lie down in an alley. receiving continued painful electric shocks. Once

\footnotetext{
* Requests for reprints should be sent to William $T$. Greenough. Department of Psychology. University of Illinois, Champaign, Ill. 61820. Supported by Grants NSF Gy 8744, $\mathrm{MH} 19135$, MH 19326, and the University of Illinois Research Board.

+ Now at the Department of Psychology, University of Colorado, Boulder, Colo.
}

it occurred. this behavior continued with additional trials.

Two explanations for the behavior were proposed by Goeckner et al. The first possibility was that these animals. already stressed by the density of the rearing environment. could not tolerate the additional stress of the complex avoidance task. The second possibility was that animals from the high-density groups were consistently faced with home cage situations (food and water availability. floor space. etc.) which they could not control. and hence developed a "learned helplessness" (Maier. Seligman, \& Solomon. 1969) which generalized to the experimental situation. In the helplessness paradigm. animals appear to learn that they have no control over inescapable and unavoidable aversive events (electric shock) in one situation. and this depresses or eliminates performance in situations in which control over the event is possible. The present experiment was designed to test if animals reared in overcrowded situations are predisposed toward learned helplessness. using a task which has been reported to produce this phenomenon in rats (Maier, Albin. \& Testa. in press).

\section{METHOD}

\section{Subjects}

A total of 112 Long-Evans hooded rats, from 24 laboratory-born litters were used in two replications. Ss were weaned at 25-26 days of age and placed in groups of 1.4 , or 32 . Twenty rats were housed singly. 28 in groups of 4 . and 64 in groups of 32 . Groups of 4 and 32 contained $25 \%$ females. Siblings were balanced as closely as possible across conditions. Isolated Ss occupied $22.5 \times 30 \times 25 \mathrm{~cm}$ (high) wire mesh cages: grouped rats were kept in $90 \times 30 \times 25 \mathrm{~cm}$ (high) wire mesh cages. Food and water were available ad lib in all cages, $14 \mathrm{~h}$ diurnal light crcle was maintained. and temperature was kept at $75^{\circ} \pm 5^{\circ} \mathrm{F}$. or $24^{\circ} \pm 3^{\circ} \mathrm{C}$. Behavioral testing began after 50 days rearing. During the testing phase. animals continued to live in their assigned environments. Twenty rats from each density level were tested: from groups larger than 20 animals. a randomized selection was used.

\section{Apparatus and procedure}

Ten animals in each density group were given inescapable electric shocks $24 \mathrm{~h}$ before escape training. Inescapable shock was administered to rats restrained in a $7.5-\mathrm{cm}-\mathrm{diam}$. $23-\mathrm{cm}-\mathrm{long}$ clear Plexiglas tube with a flat floor (Maier et al, in press). The rat's tail was taped to a rod extending from the rear of the tube, and shock electrodes coated with electrode paste were placed approximately $5 \mathrm{~cm}$ apart on the tail. The preshocked Ss received $601-\mathrm{mA}$ inescapable shocks of $5 \mathrm{sec}$ duration on a VI 1-min schedule. Nonpreshocked Ss were similarly restrained, but no shock was administered.

All Ss were tested for escape/avoidance performance in a Lehigh Valley shuttlebox $(21 \times 21 \times 45 \mathrm{~cm})$ divided into two compartments by an aluminum partition which contained a $7.5 \mathrm{~cm}$ (high) $\times 6.5 \mathrm{~cm}$ (wide) rounded opening. On each trial. the $\mathrm{S}$ was presented with a $500-\mathrm{Hz}$ tone $(8 \mathrm{~dB}$ above $73-\mathrm{dB}$ background noise). After $5 \mathrm{sec}$, electric shock $(1 \mathrm{~mA})$ was 


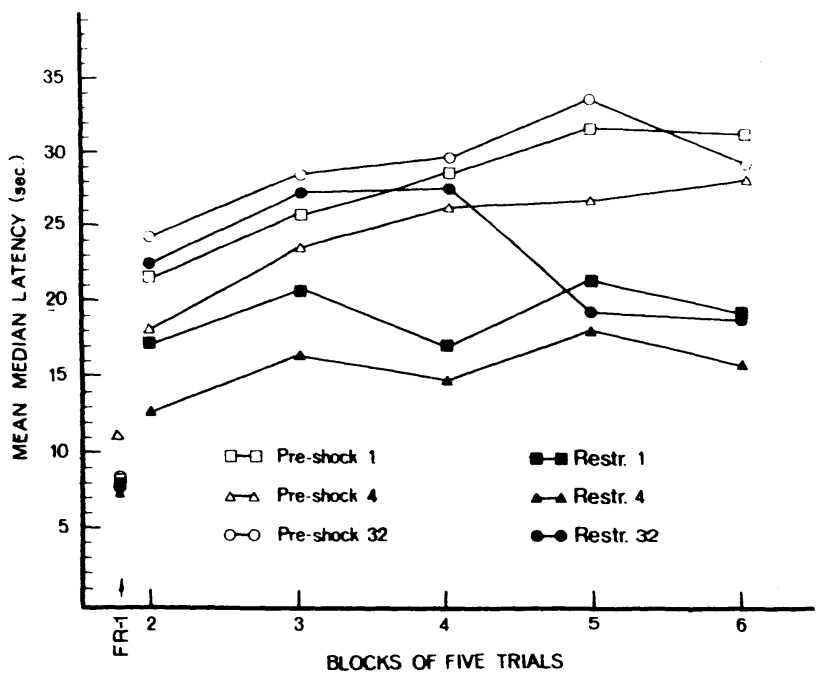

Fig. 1. Mean median response latency in seconds from CS onset, for each group, across blocks of five FR-2 shuttlebox trials, FR-1 latency is shown to the left.

delivered via the grid floor. A correct response by the $S$ terminated the tone and/or tone shock, and latency to respond was recorded. For the initial five trials, the correct response was to cross through the opening to the opposite side of the box (FR-1). For the remaining 25 trials, the rats were required to cross to the opposite side of the box and return (FR-2) in order to terminate shock. Maier et al (in press) have reported that rats show no effects of prior inescapable shock on a FR-1 shuttlebox schedule, but do fail to perform the FR-2 response. The five FR-1 trials aid naive animals in learning the subsequent FR-2 schedule. On each schedule, if the rat failed to respond within $30 \mathrm{sec}$ of shock onset, the trial was terminated and a latency of $35 \mathrm{sec}$ was recorded.

On the day following shuttlebox testing, the Ss were given a lethal dose of sodium pentobarbital and weighed. Adrenal glands were removed, cleaned of surrouding adipose tissue, and weighed.

\section{RESULTS}

Figure 1 presents the means of the median latency for each animal over blocks of five FR-2 shuttlebox trials. As can clearly be seen from Fig. 1, exposure to inescapable shock, produced failure to learn the FR-2 schedule across all populations. It is also apparent that the group of interest to this study, the nonshocked population of 32, showed an initial deficit in FR-2 performance, but ultimately reached the level of the other nonshocked groups (across nonshocked groups, Trials 21-30: $\mathrm{F}=0.46, \mathrm{df}=2,27, \mathrm{p}>.25$. Nonpreshocked Group 32 vs preshock groups: $F=7.74$, $\mathrm{df}=1,54, \mathrm{p}<.01)$. Latency over the initial five FR-1 trials was not analyzed. All Ss escaped with short latency on these trials. A preliminary analysis of variance (Population by Pretreatment by Replications, Winer, 1962) showed no significant differences between replications $(F=2.45$, df $=1.48, p>.10)$, and no interactions involving replications that approached significance. Data from the two replications were, therefore, pooled for further analysis.

For statistical evaluation, $\mathrm{S}$ medians for the first 10 and the last 10 FR-2 trials were treated as repeated measures. This analysis showed a significant depression of FR-2 responding in the preshocked groups ( $F=$ $10.98, \mathrm{df}=1,54, \mathrm{p}<.005)$. Population size was significant overall $(\mathrm{F}=3.34, \mathrm{df}=2,54, \mathrm{p}<.05)$. The Newman-Keuls range test showed the rats in groups of four to have significantly shorter median latencies than the others, and the isolates to be superior to those from the groups of 32. There was no interaction between population size and pretreatment $(\mathrm{F}=0.16, \mathrm{df}=2,54$, $\mathrm{p}>.10)$ or trial blocks $(\mathrm{F}=2.48, \mathrm{df}=2,54, \mathrm{p}>.10)$, and no three-way interaction $(\mathrm{F}=1.17 \mathrm{df}=2,54$, $\mathrm{p}>.10)$.

Analysis of body weight data, which are shown in Table 1, indicated significant effects of population size $(F=17.36 ; \mathrm{df}=2,48, \mathrm{p}<.001)$. The Newman-Keuls tests showed animals from groups of 32 to have significantly lower weights than the others, and animals from the groups of 4 to weigh significantly less than isolates. Overall differences in absolute adrenal weight were marginally reliable $(\mathrm{F}=3.11, \mathrm{df}=2,57, \mathrm{p}<.10)$. When the sizable body weight differences were taken into account by using an adrenal weight/body weight ratio (Brain \& Nowell, 1969), the differences was highly significant $(F=12.74$, df $=2,48, p<.001)$. These adrenal weights and adrenal weight/body ratios were also shown in Table 1. Rats from populations of 1 and 4 did not differ, but both had significantly lower relative adrenal weights than those from groups of 32. There were no significant interactions between the weight data and the short-term training conditions.

\section{DISCUSSION}

These findings confirm the prior report that rats rcared under crowded conditions perform more poorly on complex learning tasks than do those from moderately sized groups (Goeckner, Greenough, \& Mead, 1973). Whether group size or spatial density (or both) was the relevant variable in these studies cannot be determined (and rarely is; Bell et al, 1971). There is, however, no indication that this effect is produced by the same mechanisms that produce learned helplessness. Although rearing under crowded conditions produced an initial retardation in FR-2 escape performance, the rats in this group learned and reached the performance level of noncrowded rats. In contrast, rats exposed to inescapable shock failed to learn the FR-2 task. Past experiments indicate that, once having failed to escape, the animals will continue to fail, even across sessions (Maier et al, 1969). The pattern of responding is quite different in the previously shocked and nonshocked Ss. The latency in the nonshocked Ss tends to decrease slightly as they acquire the task over trials, while the latency of the preshocked Ss increases over

Table 1

Mean Body Weight, Adrenal Weight, and Adrenal to Body Weight Ratio for Each Population Size

\begin{tabular}{|c|c|c|c|}
\hline & \multicolumn{3}{|c|}{ Population Size } \\
\hline & 1 & 4 & 32 \\
\hline Mean body weight (g) & 341.8 & 317.0 & 287.8 \\
\hline Mean adrenal weight $(\mathrm{mg})$ & 43.5 & 45.7 & 51.5 \\
\hline $\begin{array}{l}\text { Mean adrenal weight/body } \\
\text { weight } \times 10^{4}\end{array}$ & 1.28 & 1.45 & 1.80 \\
\hline
\end{tabular}


trials (Pretreatment by Trial Blocks interaction: $F=10.64 . \mathrm{dt}=$ $1.54 . \mathrm{p}<.01)$. The animals from the groups of 32. which were expected to exhibit helplessness-like behavior. showed initially high latencies which decreased dramatically as they belatedly. acquired the task (across trial blocks. nonpreshocked Group 32: $\mathrm{F}=21.65$. df $=1.9 . \mathrm{p}<.01$ ).

An indirect outcome of the present results is a further indication of the generality of the learned helplessness phenomenon described in dogs by Overmier \& Seligman (1967). and in albino rats by Maier et al (in press) and Looney \& Cohen (1972). Exposure to uncontrollable electric shock clearly depressed FR-2 shuttlebox performance in a different strain of rats over a wide range of housing conditions.

Both body and adrenal weight data accord with previous reports (e.g., Morrison \& Thatcher, 1969; Brain \& Nowell. 1970). These data and others indicate that overcrowding is a severe stress in various species, the effects of which can be manifest in behavior. Whether the decrement in initial FR-2 performance in the present study resulted from an interaction between this social stress and the stress of the training task. or whether it may represent some more complex effect of the crowded environment upon cognitive function, remains to be determined.

\section{REFERENCES}

Bell. R. W., Miller, C. E.. Ordy, J. M., \& Rolsten, C. Effects of population density and living space upon neuroanatomy, neurochemistry, and behavior in the C57B $1 / 10$ mouse. Journal of Comparative \& Physiological Psychology, 1971, 75, 258-263.

Brain, P. F., \& Nowell. N. W. Some endocrine and behavioral changes in the development of the albino laboratory mouse. Communications in Behavioral Biology, 1969, 4, 203-220.
Brain. P. F.. \& Nowell. N. W. The effects of differential grouping on endocrine function of mature male albino mice. Physiology \& Behavior. 1970, 5, 907-910.

Calhoun, J. B. Population density and social pathology. Scientific American, 1962, 206, 139-148.

Christian. J. J. Effects of population size on the adrenal glands and reproductive organs of male mice in populations of fixed size. American Journal of Physiology, 1955, 182, 292-300.

Galle. O. R.. Gove. W. R., \& McPherson, J. M. Population density and pathology: What are the relations for man? Science. 1972, 176. 23-30.

Goeckner, D. J.. Greenough, W. T., \& Mead. W. R. Deficits in learning tasks following chronic overcrowding in rats. Journal of Personality \& Social Psychology, 1973, 28, 256-261.

Looney, T. A.. \& Cohen. P. S. Retardation of jump-up escape responding in rats pretreated with different frequencies of noncontingent electric shock. Journal of Comparative \& Physiological Psychology, 1972, 78, 317-322.

Maier, S. F.. Albin, R. W., \& Testa, T. J. Failure to learn to escape in rats previously exposed to inescapable shock depends on the nature of the escape response. Journal of Comparative \& Physiological Psychology, in press.

Maier. S. F., Seligman, M. E. P., \& Solomon, R. L. Pavlovian fear conditioning and learned helplessness: Effects on escape and avoidance behavior of (a) the CS-US contingency and. (b) the independence of the $U S$ and voluntary responding. In $B$. A. Campbell and R. M. Church (Eds.), Punishment. New York: Appleton-Century-Crofts, 1969.

Morrison, B. J., \& Thatcher, K. Overpopulation effects on social reduction of emotionality in the albino rat. Journal of Comparative \& Physiological Psychology, 1969, 69, 658-662.

Overmier, J. B., \& Seligman, M. E. P. Effects of inescapable shock upon subsequent escape and avoidance responding. Journal of Comparative \& Physiological Psychology, 1967,63. 28-33.

Winer. B. J. Statistical principles in experimental design. New York: McGraw-Hill, 1962.

(Received for publication October 19, 1973.)

\section{Changes in arousal as a function of emotional or nonemotional appraisal*}

\author{
BRUCE C. WITTMAIER \\ Eisenhower College. Seneca Falls, A.Y. 13148
}

Eighteen college freshmen were given a list of "arousal" or "relaxation" side effects after taking a placebo pill. All were then aroused by experiencing failure on a test supposedly predictive of college success. It was predicted that Ss who made an emotional appraisal of the situation (those who could not attribute

*Sponsored by Ralph Norman Haker, who takes full editorial responsibility for its contents. their arousal to the pill) would evidence a higher level of arousal by outperforming Ss making a nonemotional appraisal (those who could attribute their arousal to the pill) on a simple learning task. The prediction was confirmed.

The cognitive theory of emotion (Schachter. 1971) suggests that an emotional response is a joint function of (1) the arousal state of the person. and (2) the particular cognitions the person associates with his aroused condition. Differing cognitions can give emotional or nonemotional meaning to the arousal. In an important 